\title{
APLIKASI PENGELOLAAN DATA KEBERANGKATAN KEDATANGAN DAN PEMBONGKARAN KAPAL CARGO PADA PT. JASA SARANA BANDAR BANJARMASIN
}

\author{
Dwi Retnosari' ${ }^{1)}$ Budi Setiadi $^{2)}$ Auliya Rahman ${ }^{3)}$ \\ Fakultas Teknologi Informasi, Universitas Islam Kalimantan Muhammad Arsyad Al Banjari \\ ${ }^{1)}$ email : dwiretnosarisari@yahoo.co.id \\ Fakultas Teknologi Informasi, Universitas Islam Kalimantan Muhammad Arsyad Al Banjari \\ ${ }^{2)}$ email : budibtc75@yahoo.com \\ Fakultas Teknologi Informasi, Universitas Islam Kalimantan Muhammad Arsyad Al Banjari \\ ${ }^{3)}$ email : auliyarahmankom@gmail.com
}

\begin{abstract}
ABSTRAK
Saat ini proses pengolahan data pemberangkatan kedatangan dan pembongkaran kapal cargo di PT. Jasa Sarana Bandar Banjarmasin ini masih menggunakan cara semi komputer yaitu menggunakan Ms. Excel dan pencatatan manual dengan buku induk. Proses data tersebut masih kurang efektif dan efesien sehingga menyebabkan penyajian informasi atau laporan menjadi lambat dan kurang akurat. Selain itu, tidak adanya sistem keamanan membuat data-data yang berkaiatan dengan pembongkaran kapal cargo menjadi tidak aman dan rawan akan tindakan manipulasi data oleh pihak-pihak yang tidak memiliki kewenangan. Oleh karena itu, memandang perlu dibangunnya aplikasi khusus untuk mengelola data pembongkaran kapal cargo berbasis web. Aplikasi yang dibangun ini, dibuat dengan menggunakan tools seperti sublime, PHP, MySQL sebagai database. Metode penelitian ini menggunakan metode waterfall. Dengan ada Aplikasi Pemberangkatan Kedatangan Dan Pembongkaran Kapal Cargo di PT. Jasa Sarana Bandar Banjarmasin ini diharapkan dapat membantu petugas admin dalam mengelola dan mengontrol data dan informasi pemberangkatan kedatangan dan pembongkaran kapal cargo agar lebih akurat, cepat, efektif dan efisien.
\end{abstract}

Kata Kunci : Aplikasi, Keberangkatan Kedatangan dan Pembongkaran Kapal, PHP, MySQL

\section{PENDAHULUAN}

PT. Jasa Sarana Bandar Banjarmasin yang bergerak dibidang jasa pengiriman peti kemas ini menyediakan jasa bagi perusahaan ataupun instansi umum yang akan melakukan kegiatan pengiriman cargo, yang bertujuan untuk melakukan jasa pengiriman yang terorganisir antar pulau dan dapat lebih efesien waktu dalam mengikat peti kemas yang harus dikirimkan melalui jasa yang terpecaya secara operasional dan telah memiliki izin resmi dari pihak negara.

Pada pelayanan yang disediakan untuk pendataan cargo datang dan cargo yang akan dikirimkan serta alat transportasi yang ada pada PT. Jasa Sarana Bandar Banjarmasin saat ini masih menggunakan semi komputer seperti menggunakan Microsft Excel dan dicatat ulang pada pembukuan atau buku induk. Pada data pengiriman barang juga belum memiliki kategori khusus sehingga mudah tercampur dengan berkas data lain, penyimpanannya berupa berkas fisik berupa buku induk sehingga banyak memakan waktu dan tempat serta kurang efesien dalam pendataan dan pencarian data, dalam data pengiriman barang juga sering terjadi kesalahan yaitu data barang yang tidak sesuai penempatan, oleh karena itu sangat dibutuhkan aplikasi atau sistem informasi yang dapat mengelola dan menyimpan data dan informasi 
lebih baik agar lebih akurat dalam penyimpanan dan memudahkan dalam pencarian data dan informasi. Dengan memanfaatkan perkembangan teknologi yang menggunakan sistem terkomputerisasi untuk pengolahan data dan informasi menjadikannya sebuah media informasi yang baik, serta mampu menjalankan semua hal yang berkaitan dengan hal-hal spesifik khususnya dalam pengolahan data dan informasi cargo.

\section{METODE PENELITIAN}

Pada penelitian ini menggunakan metode waterfall, yang terdiri dari beberapa teknik dalam pembuatan penelitian ini, diantaranya :

\section{a. Requirement Analisis}

Tahapan ini pengembangan sistem diperlukan komunikasi yang bertujuan untuk memahami perangkat lunak dan perangkat keras yang diharapkan oleh pengguna. Informasi ini diperoleh melalui wawancara, diskusi dan survei langsung ke perusahaan PT. Jasa Sarana Bandar Banjarmasin, informasi dianalisis untuk mendapatkan data yang dibutuhkan oleh pengguna atau peneliti diantaranya data petugas, data invoice, data jadwal kapal, data jumlah muatan, data keberangkatan dan kedatangan dan data operasional pelabuhan.

\section{b. Sistem Design}

Spesifikasi kebutuhan dari tahap sebelumnya akan dipelajari dalam fase ini dan desain sistem disiapkan. Desain sistem membantu dalam menentukan perangkat lunak serta sistem persyaratan dan juga membantu dalam mendefinisikan arsitektur dalam aplikasi secara keseluruhan. Perangkat lunak digunakan untuk aplikasi agar dapat berjalan dalam melakukan tugasnya, adapun yang diperlukan dalam sistem ini adalah Sublime Text 3, XAMPP, PHP, MySQL, Draw.io

Sedangkan desain tabel database untuk menghubungkan data adalah sebagai berikut :
a. Tabel Jadwal Kapal
b. Tabel Jumlah Muatan
c. Tabel Keberangkatan
d. Tabel Kedatangan
e. Tabel Opersional Pelabuhan
f. Tabel Pembongkaran Barang

Sedangkan model sistem pada Aplikasi Pengelolaan Data Keberangkatan Kedatangan Dan Pembongkaran Kapal Cargo Pada PT. Jasa Sarana Bandar Banjarmasin.

1) Use Case Diagram

Data Use Case Diagram Aplikasi Pengelolaan Data Keberangkatan Kedatangan Dan Pembongkaran Kapal Cargo Pada PT. Jasa Sarana Bandar Banjarmasin.

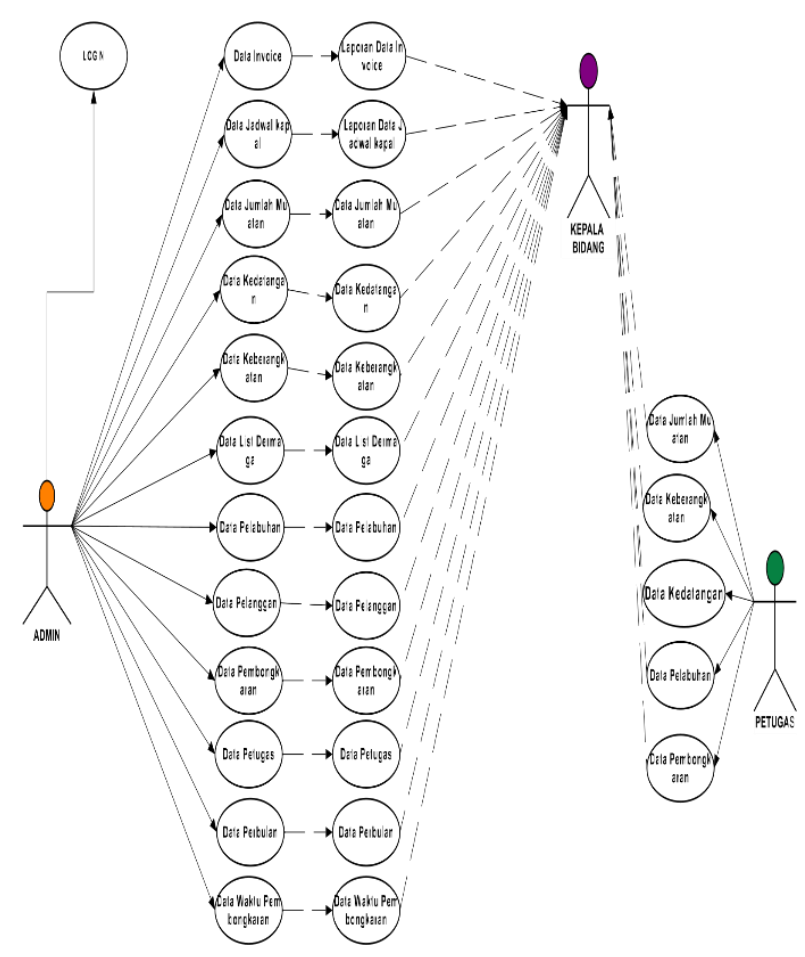

Gambar 2. 1 Use Case Diagram

2) Activity Diagram

Activity Diagram Aplikasi

Pengelolaan Data Keberangkatan Kedatangan Dan Pembongkaran Kapal Cargo Pada PT. Jasa Sarana Bandar Banjarmasin. 


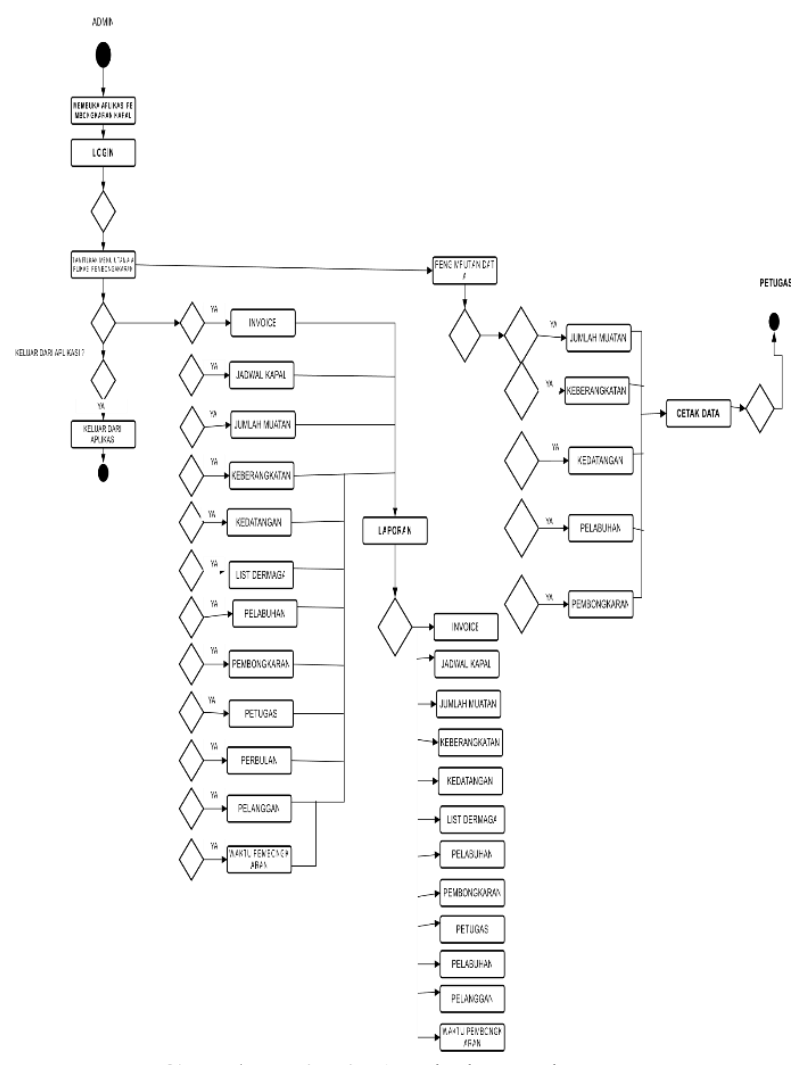

Gambar 2. 2 Activity Diagram

3) Sequence Diagram

Data Sequence Diagram Aplikasi Pengelolaan Data Keberangkatan Kedatangan Dan Pembongkaran Kapal Cargo Pada PT. Jasa Sarana Bandar Banjarmasin.

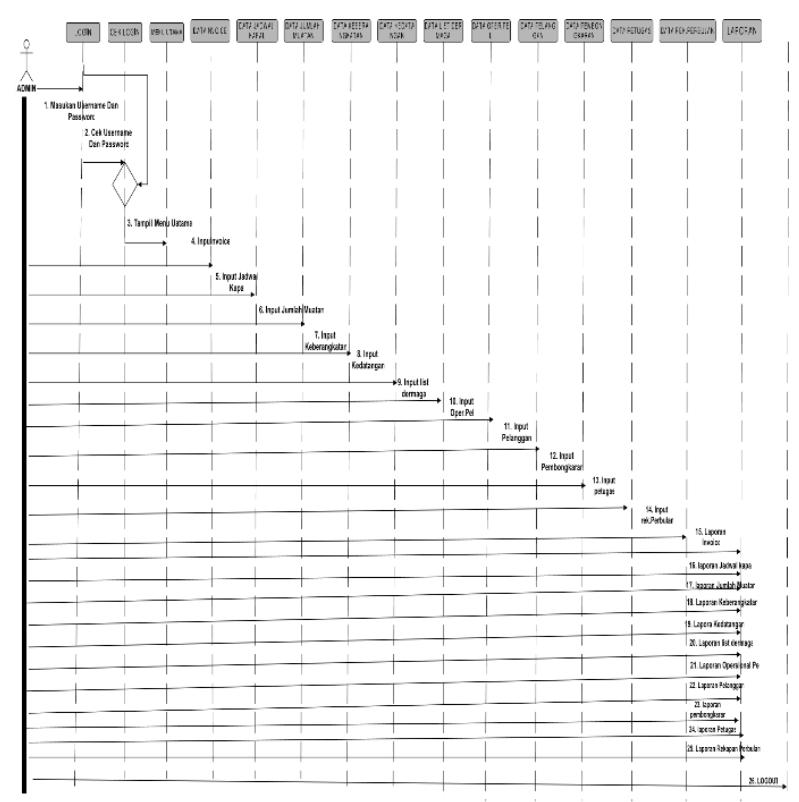

Gambar 3. 3 Sequence Diagram

Gambar 2. 3 Sequence Diagram
4) Class Diagram

Data Class Aplikasi Pengelolaan Data

Keberangkatan Kedatangan Dan

Pembongkaran Kapal Cargo Pada PT. Jasa Sarana Bandar Banjarmasin.

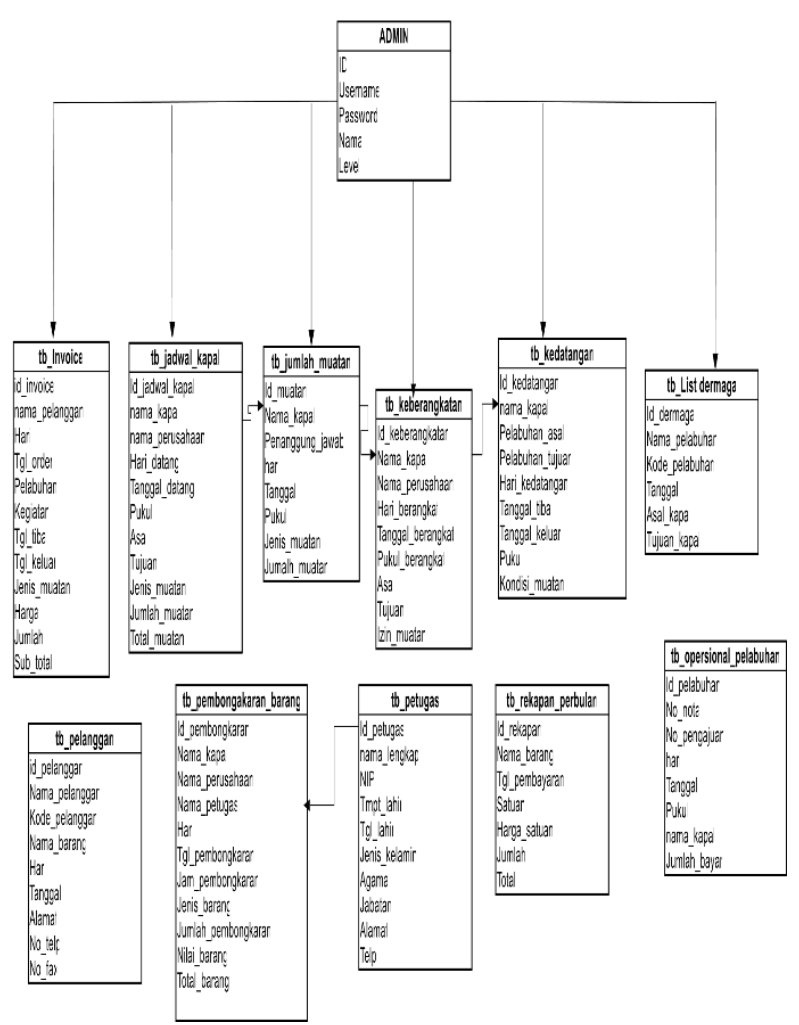

Gambar 2. 4 Class Diagram

\section{c. Implementation}

Pada tahapi ini, Aplikasi Pengelolaan Data Keberangkatan Kedatangan Dan Pembongkaran Kapal Cargo Pada PT. Jasa Sarana Bandar Banjarmasin menggunakan Web pertama kali dikembangkan dan dijalankan dalam tampilan di program kecil yang disebut unit, yang terintegrasi dalam tahap selanjutnya. Setiap unit dikembangkan dan diuji untuk fungsionalitas yang disebut sebagai unit testing mengunakan XAMPP, PHP, MySQL.

\section{d. Integration \& Testing}

Seluruh unit yang dikembangkan dalam tahap implementasi diintegrasikan ke dalam aplikasi pengujian yang dilakukan masing-masing unit. Setelah integrasi seluruh sistem diuji untuk mengecek setiap kegagalan maupun kesalahan. 


\section{e. Operation \& Maintenance}

Tahap akhir dalam metode waterfall. Dilakukan pemeliharaan termasuk dalam memperbaiki kesalahan yang tidak ditemukan pada langkah sebelumnya. Perbaikan implementasi unit system sebagai kebutuhan baru supaya aplikasi ini bisa berjalan sebagaimana mestinya.

\section{HASIL DAN PEMBAHASAN}

Hasil dari penelitian ini adalah terciptanya Aplikasi Pengelolaan Data Keberangkatan Kedatangan Dan Pembongkaran Kapal Cargo Pada PT. Jasa Sarana Bandar Banjarmasin yang dapat mempermudah dalam mengelola data dan informasi serta agar semua sistem dapat terintegrasi dan terkomputerisasi dengan baik sehingga menghasilkan data dan informasi yang akurat, cepat, efektif dan efesien.

Berikut tampilan form Aplikasi Pengelolaan Data Keberangkatan Kedatangan Dan Pembongkaran Kapal Cargo Pada PT. Jasa Sarana Bandar Banjarmasin.

\section{a. Halaman Menu Form Login}

Desain form login merupakan langkah untuk masuk ke menu utama agar dapat menjalankan aplikasi ini, pada tahapan ini User harus mengikuti Username dan Password.

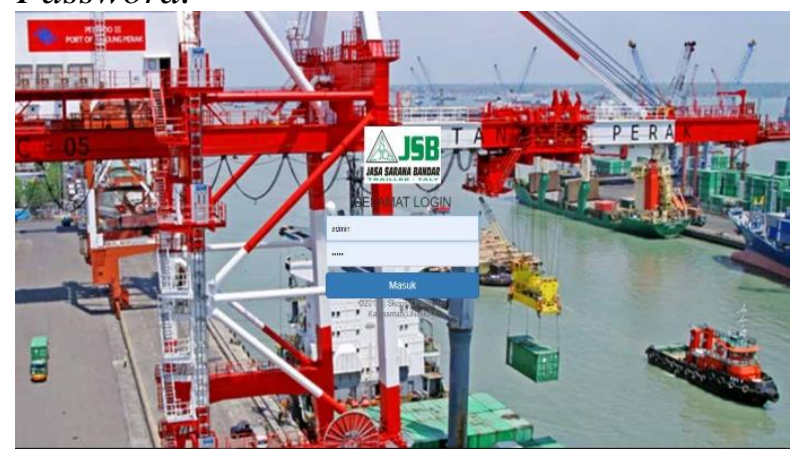

Gambar 3. 1 Menu Login

\section{b. Tampilan Halaman Menu Utama}

Pada halaman ini admin dapat mengelola website dengan memilih menu yang disediakan pada sisi sebelah kiri dimana pada menu tersebut disediakan, akses untuk menampilkan, menambah, mengedit dan menghapus data.

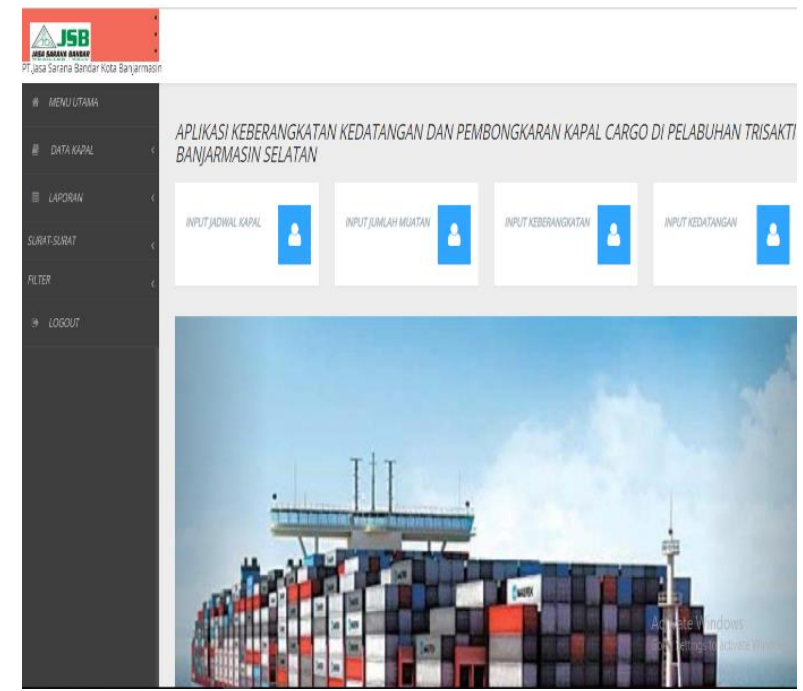

Gambar 3.2 Tampilan Menu Utama

c. Inputan Data Invoice

Menampilkan form data invoice dengan inputan seperti nama petugas, no pengajuan, hari, tanggal order, pelabuhan, kegiatan tanggal tiba,, tanggal keluar, dan lain-lainnya seperti pada gambar diatas dengan tombol aksi simpan untuk menyimpan data ke database dan tombol reset untuk mengosongkan form inputan.

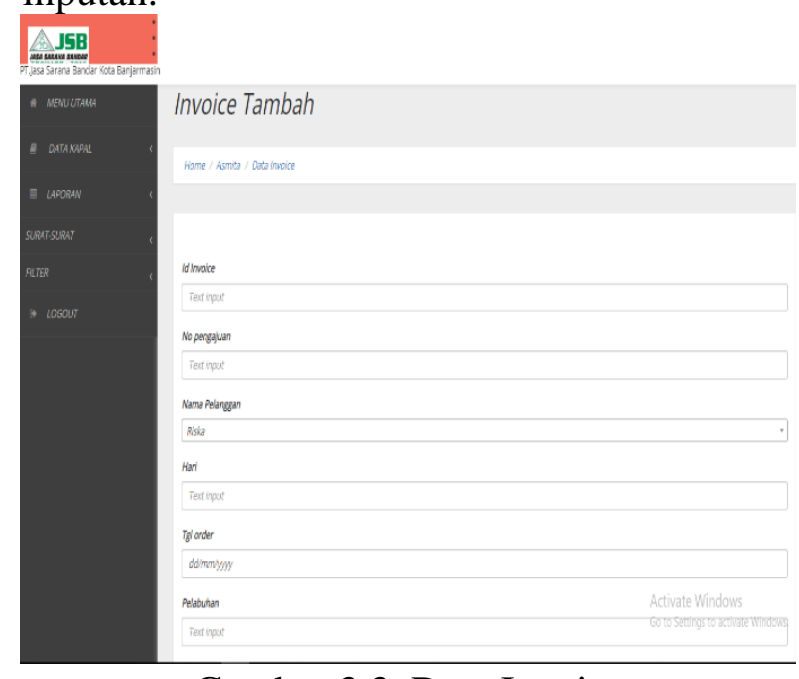

Gambar 3.3 Data Invoice

d. Data Jadwal Kapal

Menampilkan form data jadwal kapal dengan inputan seperti nama kapal, namaperusahaan, hari datang, tanggal datang, pukul, asal, tujuan, dan lainnya seperti pada gambar diatas dengan tombol aksi simpan untuk menyimpan data ke database dan tombol reset untuk mengosongkan form inputan. 


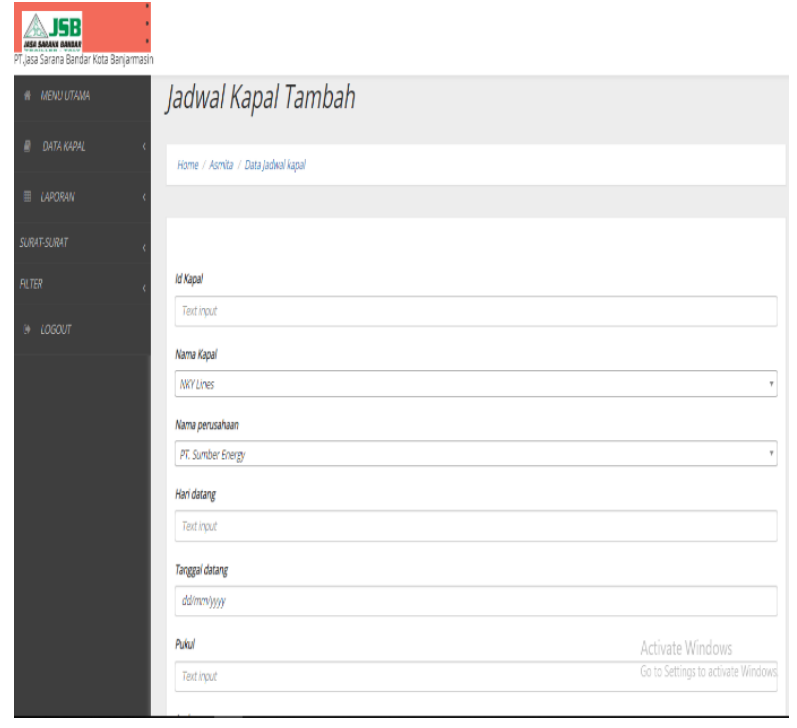

Gambar 3.4 Data Jadwal Kapal

e. Data Jumlah Muatan

Menampilkan form data jumlah muatan dengan inputan seperti nama kapal, nama perusahaan, penanggung jawab, hari, tanggal muatan seperti pada gambar diatas dengan tombol aksi simpan untuk menyimpan data ke database dan tombol reset untuk mengosongkan form inputan.

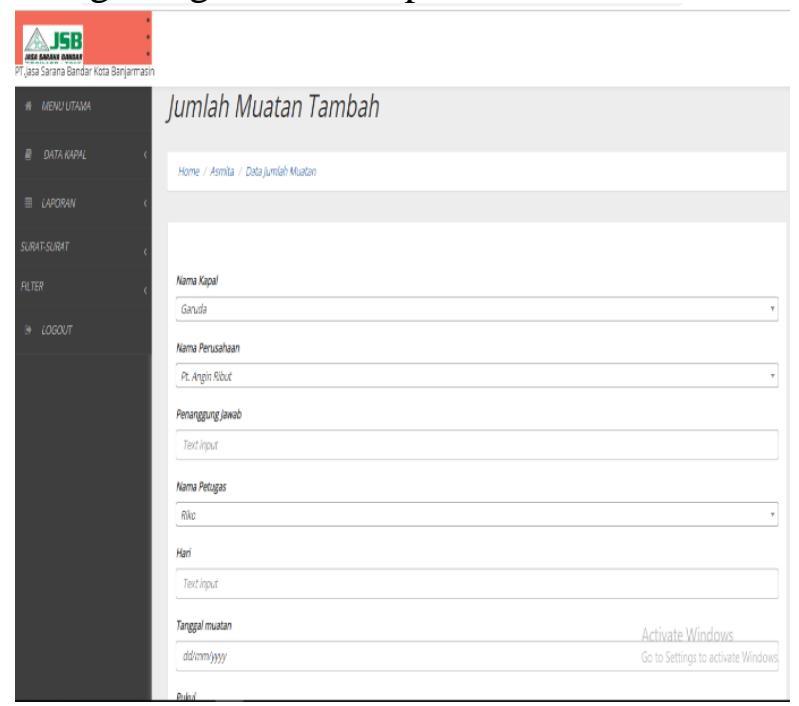

Gambar 3.5 Data Jumlah Muatan

\section{f. Data Keberangkatan}

Menampilkan form data keberangkatan dengan inputan seperti nama kapal,nama perusahaan, hari berangkat, tanggal berangkat, seperti pada gambar diatas dengan tombol aksi simpan untuk menyimpan data ke database dan tombol reset untuk mengosongkan form inputan.

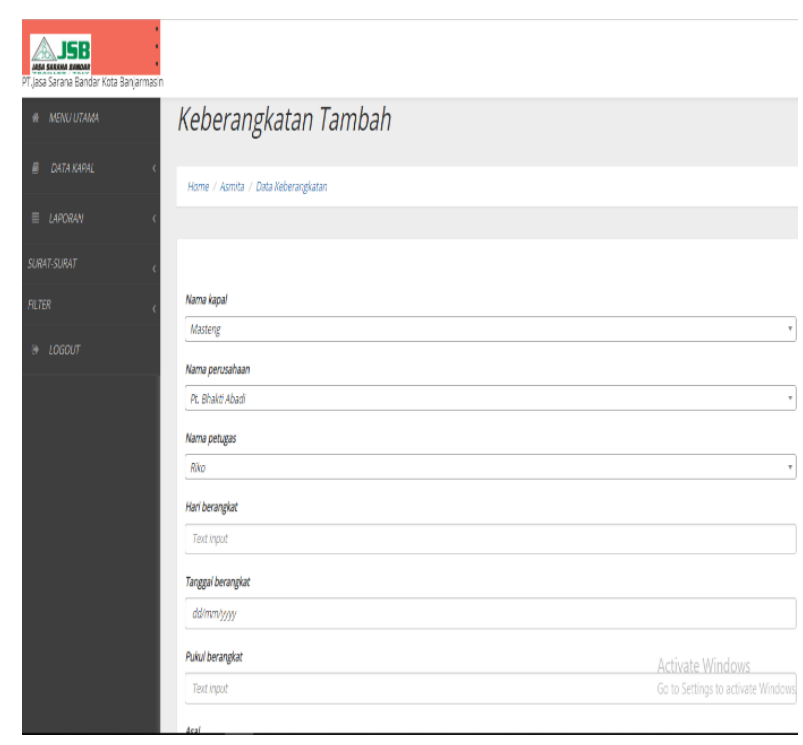

Gambar 3.6 Data Keberangkatan

\section{g. Data Kedatangan}

Menampilkan form simpan data kedatangan dengan inputan seperti nama kapal, pelabuhan asal, pelabuhan asal, hari kedatangan, tanggal tiba dan lain-lainnya seperti pada gambar diatas dengan tombol aksi simpan untuk menyimpan data ke database dan tombol reset untuk mengosongkan form inputan.

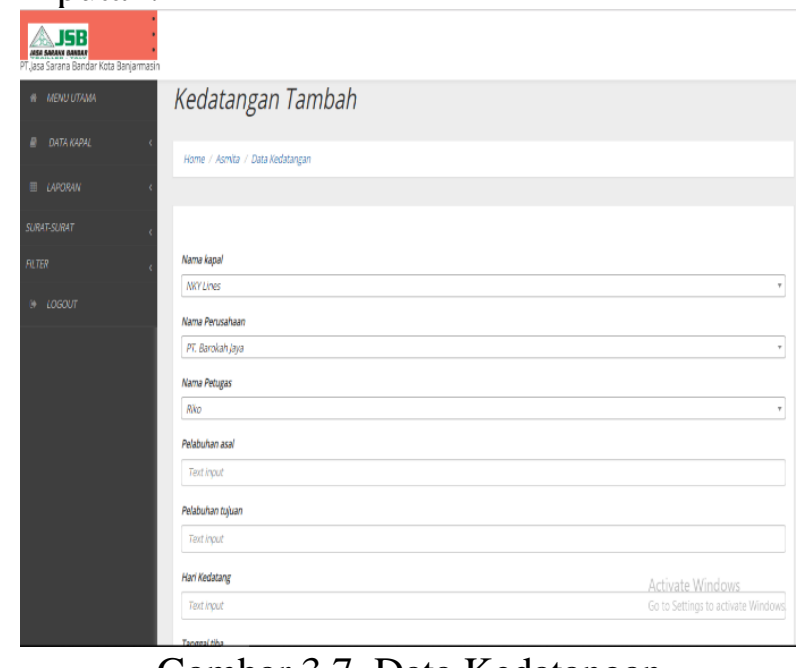

Gambar 3.7 Data Kedatangan

\section{h. Data List Dermaga}

Menampilkan form simpan data list dermaga dengan inputan seperti nama pelabuhan, kode pelabuhan, tanggal, asal kapal, seperti pada gambar diatas dengan tombol aksi simpan untuk menyimpan data ke database dan tombol reset untuk mengosongkan form inputan. 


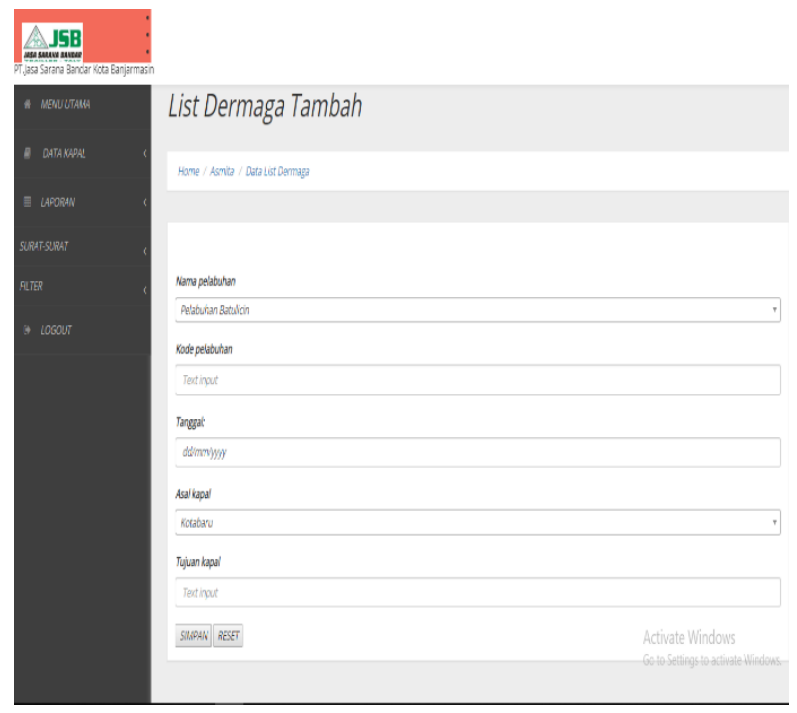

Gambar 3.8 Data List Dermaga

i. Data Opersional Pelabuhan

Menampilkan form simpan data list dermaga dengan inputan seperti no nota, no pengajuan, hari, tanggal, pukul dan lainlainnya seperti pada gambar diatas dengan tombol aksi simpan untuk menyimpan data ke database dan tombol reset untuk mengosongkan form inputan.

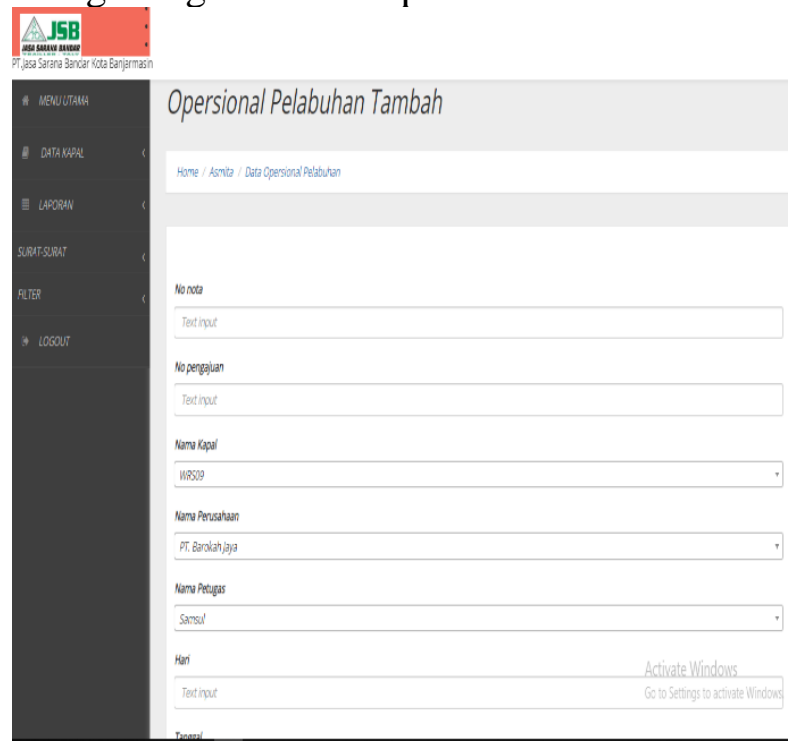

Gambar 3.9 Data Opersional Pelabuhan

j. Inputan Data Pelanggan

Menampilkan form data pelanggan dengan inputan seperti nama pelanggan, kode pelanggan, hari, tanggal seperti pada gambar diatas dengan tombol aksi simpan untuk menyimpan data ke database dan tombol reset untuk mengosongkan form inputan.

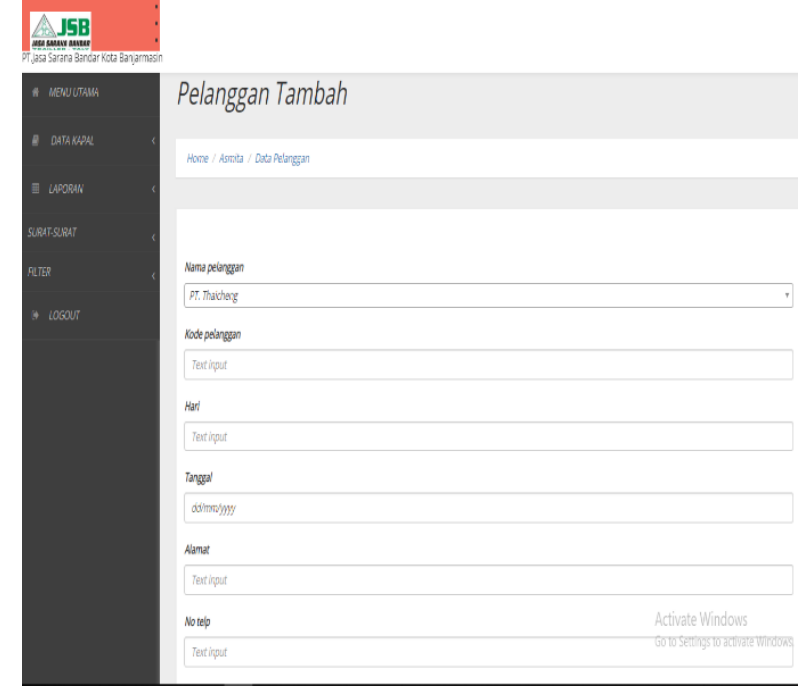

Gambar 3.10 Data Pelanggan

k. Inputan Data Pembongkaran Barang

Menampilkan form data pembongkaran barang dengan inputan seperti nama kapal, nama perusahaan, nama petugas, hari, tanggal pembongkaran dan lain-lainnya seperti pada gambar diatas dengan tombol aksi simpan untuk menyimpan data ke database dan tombol reset untuk mengosongkan form inputan.

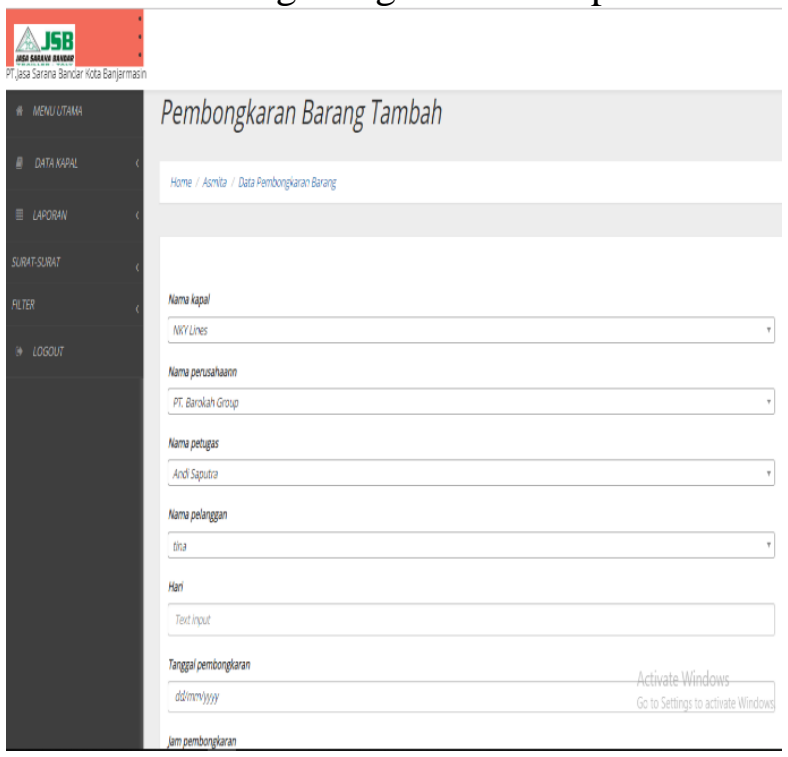

Gambar 3.11 Data Pembongkaran Barang

1. Inputan Data Petugas

Menampilkan form data petugas dengan inputan seperti nama lengkap, nip, tempat lahir, jabatan dan lain-lainnya seperti pada gambar diatas dengan tombol aksi simpan untuk menyimpan data ke database dan tombol reset untuk mengosongkan form. 


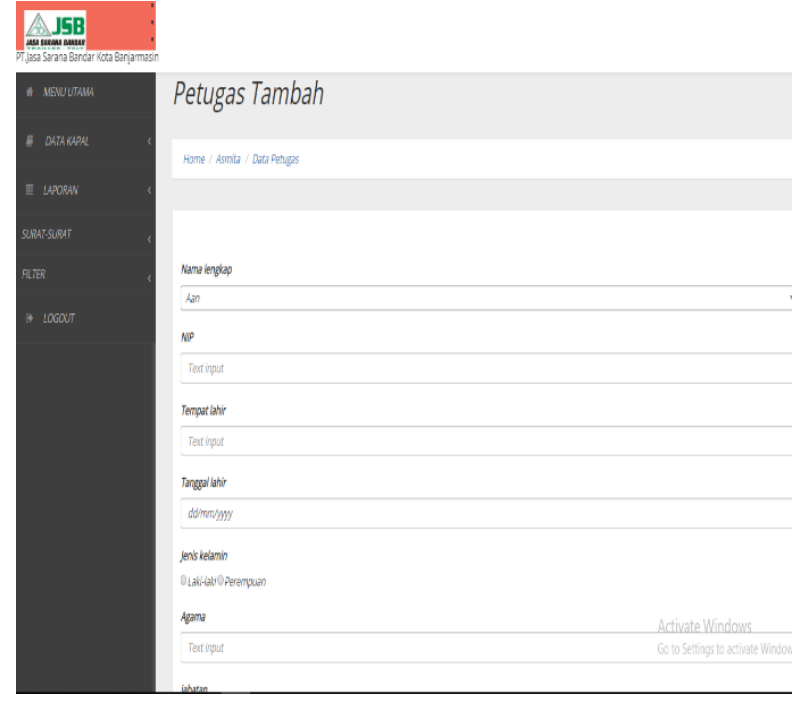

Gambar 3.12 Data Petugas

Berikut tampilan laporan atau report Aplikasi Pengelolaan Data Keberangkatan Kedatangan Dan Pembongkaran Kapal Cargo Pada PT. Jasa Sarana Bandar Banjarmasin.

a. Laporan Invoice

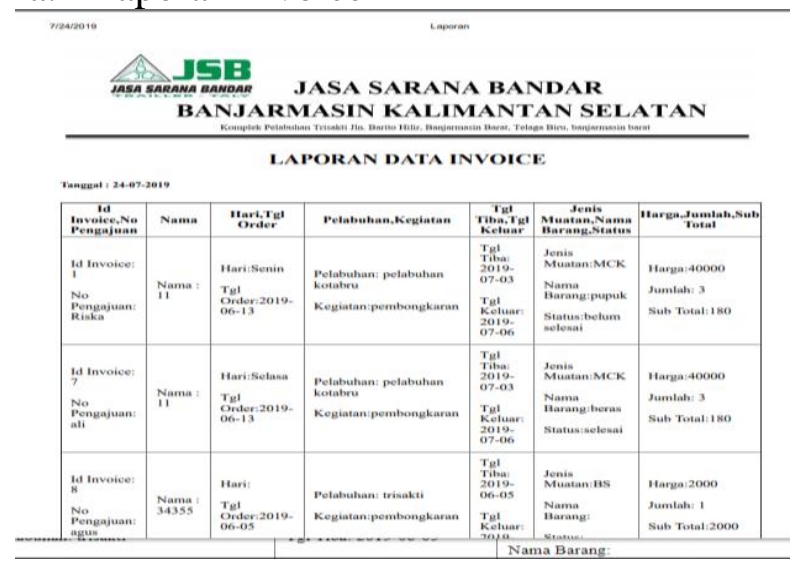

Gambar 3. 13 Laporan Invoice

b. Laporan Jadwal Kapal

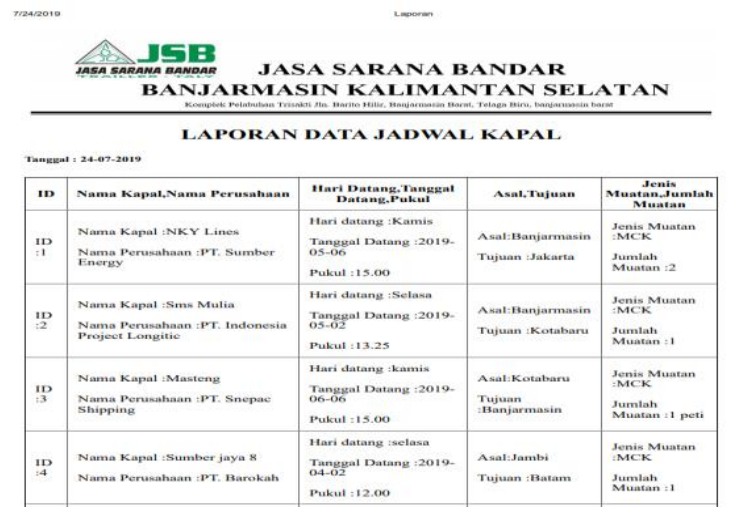

Gambar 3.14 Laporan Jadwal Kapal

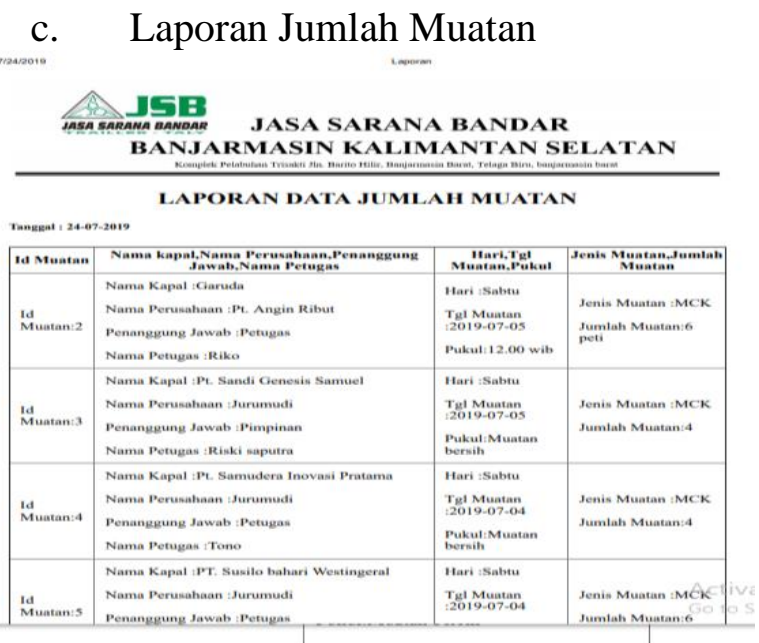

Gambar 3. 15 Laporan Jumlah Muatan

d. Laporan Keberangkatan

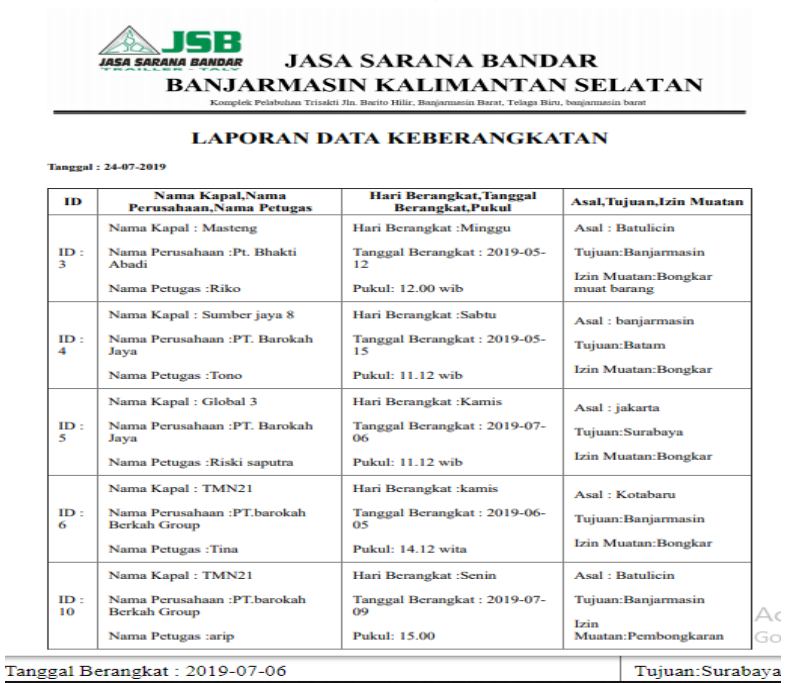

Gambar 3.16 Laporan Keberangkatan

e. Laporan Kedatangan

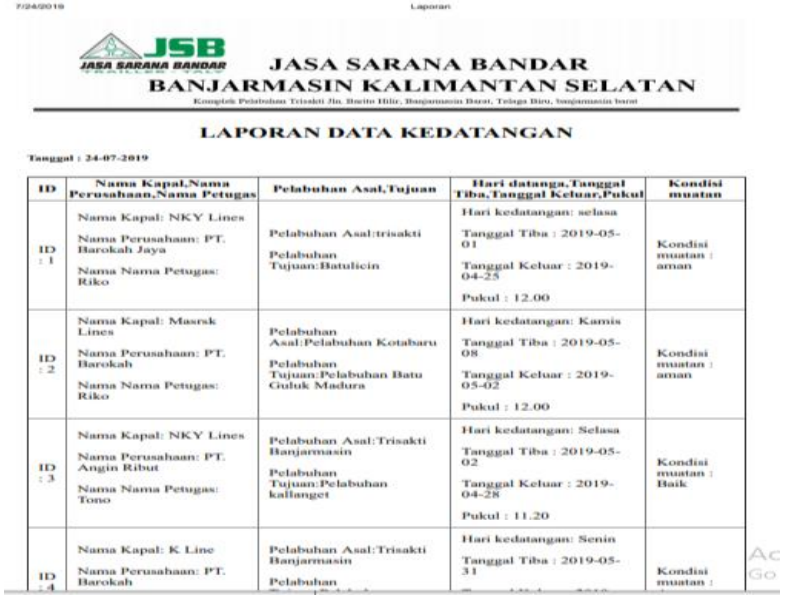

Gambar 3.17 Laporan Kedatangan

Jurnal Ilmiah "Technologia" 
f. Laporan List Dermaga

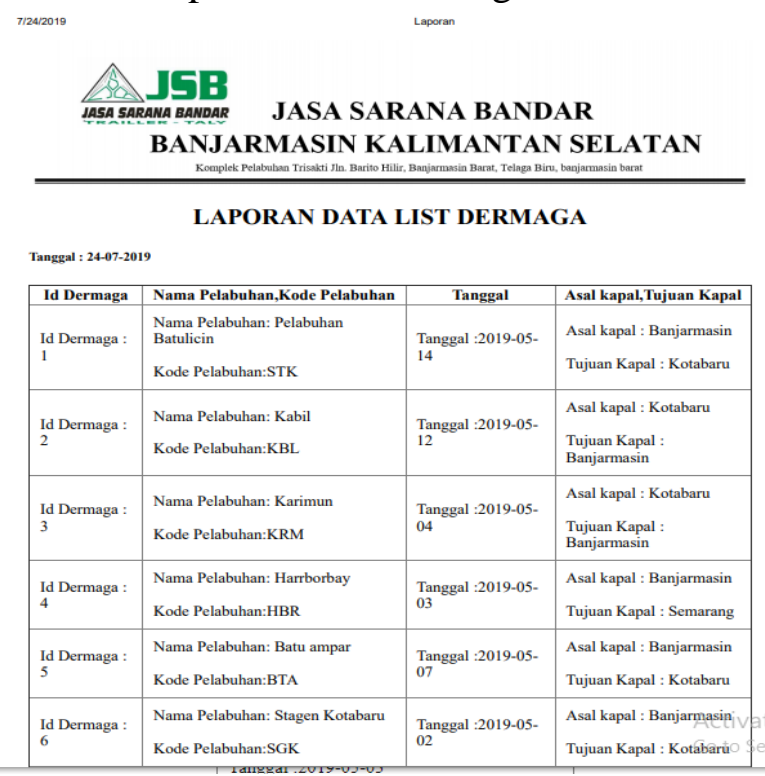

Gambar 3.18 Laporan List Dermaga

g. Laporan Opersional Pelabuhan

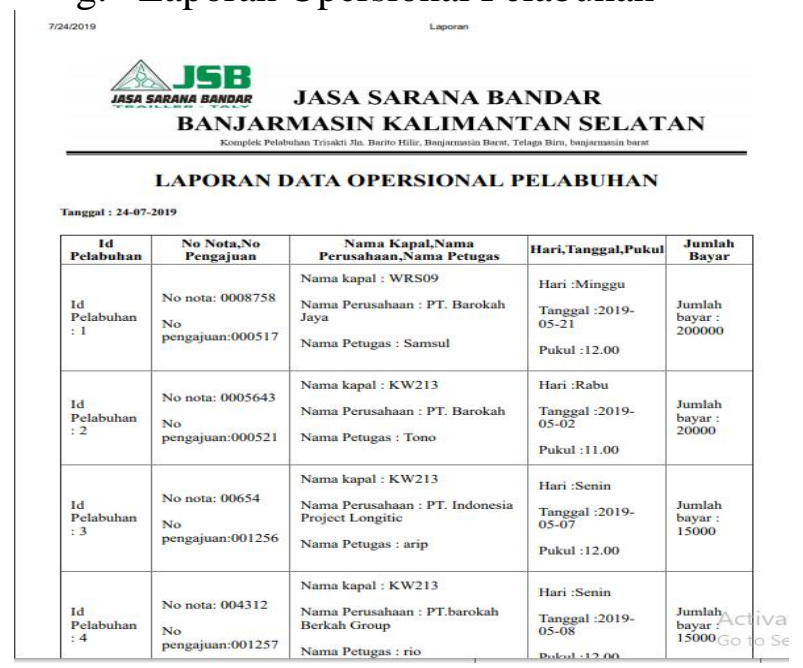

Gambar 3. 19 Laporan Opersional Pelabuhan

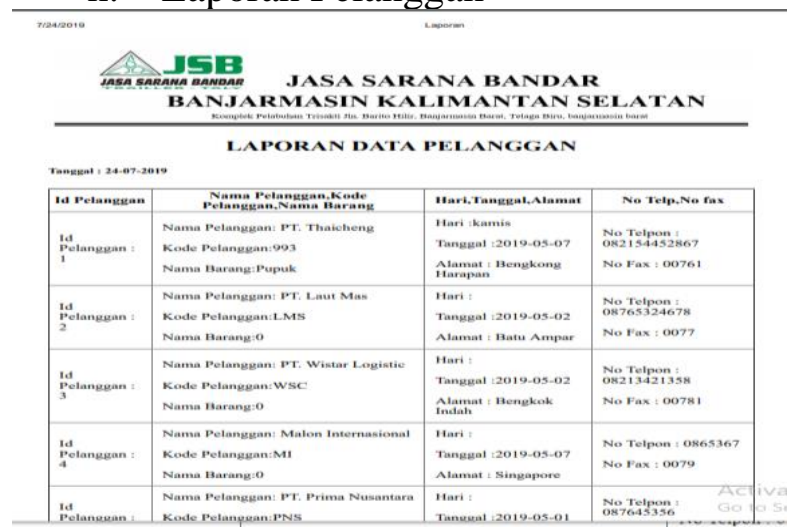

Gambar 3. 20 Laporan Pelanggan i. Laporan Pembongkaran Barang

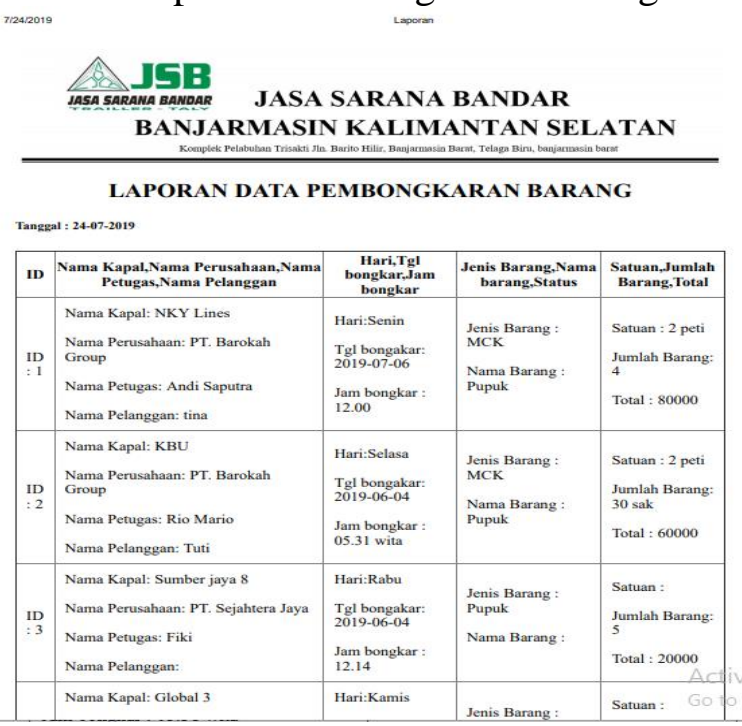

Gambar 3. 21 Laporan Pembongkaran Barang

\section{j. Laporan Petugas}
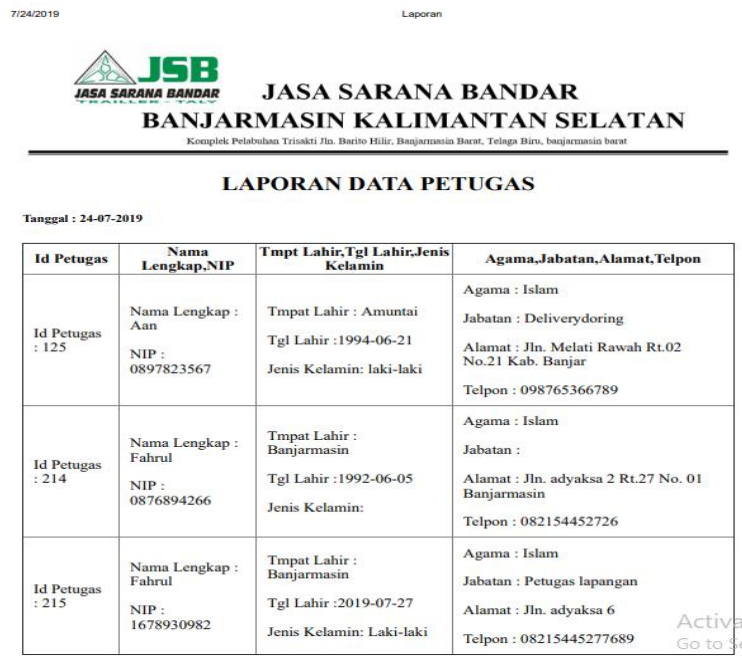

Gambar 3. 22 Laporan Petugas

\section{KESIMPULAN}

Berdasarkan hasil dari penelitian yang telah dilaksanakan dapat ditarik kesimpulan sebagai berikut :

1. Dengan diterapkannya aplikasi pemberangkatan kedatangan dan pembongakaran kapal cargo segala kendala tentang keterlambatan dan ketidak akuratan dalam laporan-laporan yang berhubungan masalah dengan datadata kapal dan yang lain dapat diatasi serta 
penyimpanan data-data lebih cepat, akurat dan efisien.

2. Dengan diterapkannya aplikasi ini dapat memudahkan antara petugas/admin dalam menginputkan atau mengelola data dan informasi.

3. Dari proses pembuatan aplikasi pemberangkatan kedatangan dan pembongkaran kapal cargo ini bisa memberikan solusi dari masalah-masalah yang ada.

\section{REFERENSI}

Akbar, E. Y. (2017). Mal Administrasi Dalam Proses Pembongkaran Petikemas Di PT. Pelabuhan Indonesia IV (persero) Cabang Terminal Petikemas. Makassar.

Berndtssom, M., Hansson, J., Olsson, B., \& Lundell, B. (2008). A Guide For Students In Computer Science And Information Systems. London: Springer.

Jogiyanto, H. (1992). Pengenalan Komputer. Yogyakarta: Andi Offset.

Firmansyah. (12 januari, 2018). Pengertian MySQL Beserta Fungsi dan Sejarah Terbentuknya MySQL Secara Lengkap. Retrieved from www.nesabamedia.com:

https://www.nesabamedia.com/penge rtian-mysql/

Indrajani. (2008). Konsep Dasar Data Dan Informasi. Retrieved from Metode Belajar:

http://metode1.blogspot.com/2015/07/ konsep-dasar-data-dan-informasi.html

Idas, k. (12 maret, 2015). Definisi dan Pengertian Informasi Menurut Para Ahli. Retrieved from http://www.definisipengertian.com: http://www.definisipengertian.com/2015/03/definisidan-pengertian-informasi.html
Kurniawan, F. (25 juli, 2017). Pengertian Sistem Secara Umum dan Menurut Para Ahli. Retrieved from http://fredikurniawan.com: http://fredikurniawan.com/pengertian sistem-secara-umum-dan-menurutpara-ahli/

Witjaksosno, A. (2016). Pengolaan Waktu Endap Dan Tingkat Kepadatan Lapangan Penumpukan Peti Kemas Di PT. Jakarta Internasional Container Terminal. 
